\title{
Sublingual Misoprostol in the Management of First Trimester Missed Abortion
}

\author{
Dr. Padma Palania ${ }^{1 *}$, Dr. K.P. Banerjee ${ }^{1}$, Dr. Rakhi Arya ${ }^{1}$
}

${ }^{1}$ Department of Obstetrics and Gynecology, SMS Medical College, Jaipur, Rajasthan, India

DOI: $10.36347 /$ sjams.2021.v09i04.011

| Received: 04.03.2021 | Accepted: 05.04.2021 | Published: 11.04.2021

*Corresponding author: Dr. Padma Palania

Abstract

Original Research Article

Aim: The aim of the present study is to study the efficacy of sublingual administration of misoprostol in the management of missed abortion. Materials and Methods: It was a randomized controlled study conducted in Department of Obstetrics \& Gynaecology, SMS Medical College, Jaipur on 120 patients diagnosed as missed abortion by ultrasonographic examination. Cases were given- tab misoprostol $400 \mathrm{~g}$ sublingually every 3 hrs for maximum of 4 doses. Patients were observed for the induction-abortion interval, amount of vaginal bleeding, number of doses required, presence of RPOC, need for evacuation and side-effects. Result: During the follow-up of our cases we found that sublingual route is effective in the management of missed abortion. 78.33\% women had complete abortion and do not require evacuation .Mean induction abortion interval was 11.01 hours. Mean dose required was $1084 \mathrm{mg}$, these women experienced side effects including nausea and vomiting (20\%) and diarrhoea (16.67\%), fever (15\%). Conclusion: Sublingual administration of misoprostol is effective in missed abortion management.

Keywords: Misoprostol, sublingual, missed abortion, ultrasonographic examination.

Copyright (C) 2021 The Author(s): This is an open-access article distributed under the terms of the Creative Commons Attribution 4.0 International License (CC BY-NC 4.0) which permits unrestricted use, distribution, and reproduction in any medium for non-commercial use provided the original author and source are credited.

\section{INTRODUCTION}

Missed abortion is defined as death of conceptus without expulsion of its contents with closed cervix before fetal viability. Abortion occurs in approximately 10-20\% of all pregnancies. The risk of spontaneous abortion increases with old maternal age, high gravidity, and increased paternal age [1]. Successful pregnancy is dependent on the integration of complex genetic, hormonal, immunologic and cellular events, and must involve complete cooperation during the conception, implantation and evolution of the embryo [2].

Management of missed abortion includes the following: Surgical evacuation and Medical evacuation [3]. Surgical procedures to terminate pregnancy include dilatation and curettage, aspiration and evacuation. Medical management of first trimester abortions has significant economic advantages over traditional surgical management $[4,5]$.

Missed abortion is usually associated with bulky pregnancy products and its adherence to the uterine wall and closed cervix; that is why, surgical management may be complicated by incomplete evacuation, uterine perforation, and cervical trauma [6].
However, the costs of surgery and hospitalization, as well as the complications associated with surgery and anaesthesia are a major unresolved concern. Besides infection and bleeding, decreased fertility caused by intrauterine adhesions may be unacceptable for women with missed abortion, who have not yet fulfilled their motherhood desires [7].

Misoprostol is a synthetic prostaglandin E1 (PGE1) analog that is used for gastritis and gastric ulcers 'treatment, to induce labor, and as an abortifacient. Absorption of misoprostolic acid is rapid in reaching peak plasma concentration within 15-30 min and has a plasma half-life of 13-40 min. It can be used as oral, sublingual, buccal (between the cheeks and the gums), vaginal, and rectal routes [6].

However several problems have been identified with vaginal misoprostol like inconsistent absorption and incomplete absorption in addition to women finding vaginal administration uncomfortable [8-10]. Misoprostol given vaginally though took longer for onset and had a lower peak (peak concentration after 60 minutes it had a more sustained effect as compared to oral misoprostol). Subsequently a new route of giving misoprostol by sublingually. The sublingual mucosa, being very vascular, serves the purpose of better 
Padma Palania et al; Sch J App Med Sci, Apr, 2021; 9(4): 546-548

absorption. Sublingual application also avoids the first pass effect through the liver.

This study was undertaken to see the efficacy of $400 \mu \mathrm{g}$ sublingual misoprostol with, in repeated doses, for medical management of missed miscarriage.

\section{Material and Methods}

This study was randomized control study conducted at SMS Medical College Jaipur

\section{Inclusion Criteria}

- Gestational sac with mean sac diameter of $>25 \mathrm{~mm}$, without fetal pole (blighted ovum).

- The presence of fetal pole $>7 \mathrm{~mm}$, with no cardiac pulsations.

- Gestational sac mean diameter $<18 \mathrm{~mm}$, with no interval growth being observed on rescanning 10 days later.

- The absence of embryo with heartbeat at least 2 weeks after an ultrasound scan that showed a gestational sac without a yolk sac.

- The absence of embryo with heartbeat at least 11 days after an ultrasound scan that showed a gestational sac with a yolk sac

- Women giving informed consent

\section{Exclusion Criteria}

- Incomplete abortion

- $\mathrm{RPOC}$

- $\mathrm{Hb}<8 \mathrm{~g} / \mathrm{dl}$

- Coagulopathy or anticoagulant therapy

- Glaucoma

- Inherited porphyria

- Hypersensitivity to these drugs

- Bronchial asthma

\section{Methodology}

- All the cases were subjected to full history taking, including age, gravity, parity, last menstrual period (LMP), and present complaint (e.g., amenorrhea, regression of symptoms of pregnancy, pain, bleeding), complete general examination, obstetric examination, and transvaginal ultrasound examination to confirm the diagnosis. Cases were given $400 \mu \mathrm{g}$ of misoprostol sublingually every three hours for a maximum of 4 doses.

- From intake of the first dose till $24 \mathrm{hrs}$ after the last dose, follow-up was done and closely observed for induction-abortion interval, amount of vaginal bleeding (excessive if $>2 \mathrm{pad} / \mathrm{hr}$ for $>2$ hours) gastrointestinal side effects such as nausea, diarrhea, stomach cramps.

- USG was repeated after $24 \mathrm{~h}$ after the last dose and after expulsion of parts of conception to assure complete evacuation of the uterine cavity.

- The absence of remnant of conception or endometrial interface thickness less than $15 \mathrm{~mm}$ was mandatory to diagnose complete abortion.
- Surgical evacuation was done in all other cases that showed no uterine colic, internal os dilatation, and complete evacuation with endometrial interface more than $15 \mathrm{~mm}$ within $24 \mathrm{~h}$ from the last dose.

- $\quad \mathrm{Rh}$ anti $\mathrm{D}$ was given to $\mathrm{Rh}-$ ve mother.

\section{RESULTS}

Table-1: Distribution of Cases According to Need for Surgical Evacuation

\begin{tabular}{|c|r|r|}
\hline Need for Surgical Evacuation & \multicolumn{1}{|c|}{ No. } & \multicolumn{1}{c|}{$\%$} \\
\hline Required & 26 & 21.67 \\
\hline Not Required & 94 & 78.33 \\
\hline Total & 120 & 100.00 \\
\hline \multicolumn{2}{|c|}{} \\
$p=0.0021$
\end{tabular}

Table-2: Distribution of Cases According to Sideeffects

\begin{tabular}{|c|r|r|}
\hline Side-effects & \multicolumn{1}{|c|}{ No. } & \multicolumn{1}{c|}{$\%$} \\
\hline Nausea / Vomiting & 24 & 20.00 \\
\hline Diarrhoea & 20 & 16.67 \\
\hline Fever / Chills & 18 & 15.00 \\
\hline Excessive Bleeding & 8 & 6.67 \\
\hline
\end{tabular}

\section{DiscUSSION}

In this study, mean age was $25.86 \pm 4.19$ yrs. Maximum women belonged to middle class - 93.33. Maximum women came with chief complaint of bleeding per vaginum i.e. $88.33 \%$. Other less common complaints were pain abdomen, and brownish discharge. $14.17 \%$ women came as routine check-up whose USG showed missed abortion. Majority of women had absent fetal heart pulsation or absent fetal pole i.e. $106(88.30 \%)$. The other findings were blighted ovum seen in $11.6 \%$ women. Primigravida were 56 $(46.67 \%)$ in this study. Mean gestational age was $7.90 \pm$ 1.37 wks. Mean dose of misoprostol in Group-A was $2.71 \pm 0.90 .83(69.17 \%)$ women had inductionabortion interval between 6-12 hrs. $11(9.17 \%)$ women aborted within 12-18 hrs.

In this study 26 (21.67\%) had shown retained product of conception in USG and require evacuation. In our study, we found that $78.33 \%$ women had complete abortion and did not require evacuation. Shah $\mathrm{N}$ et al. [12] study reported that after giving $400 \mathrm{~g}$ misoprostol sublingually and vaginally repeated every 3 hours found that complete abortion occurred in $52 \%$ in sublingual group and $48 \%$ in vaginal group. The explanation for this difference was that it had extended the gestational age of cases upto 20 weeks. Aly $\mathrm{HH}$ et al. [6] study using $100 \mathrm{~g}$ sublingual and vaginal misoprostol every $4 \mathrm{hrs}$ found that complete abortion occur in $70 \%$ in sublingual group and $51.25 \%$ in vaginal group and the difference between both groups in relation to expulsion rates was significant. Park JY et al. [13] study found that after giving $600 \mathrm{~g}$ misoprostol sublingually $61.5 \%$ had a successful outcome. Similar 
Padma Palania et al; Sch J App Med Sci, Apr, 2021; 9(4): 546-548

to our study, Sharma P et al. [14] reported in their study that complete abortion occur in $62 \%$ in Group-1 (vaginal) and $80 \%$ in sublingual group which was comparable to our study. Thakur $\mathrm{S}$ et al. [15] study reported that after giving $200 \mathrm{mg}$ mifepristone and then after $48 \mathrm{hrs}$, using $600 \mathrm{~g}$ and $800 \mathrm{~g}$ misoprostol found that complete abortion occur in $>90 \%$ cases. The explanation for this difference is that they had given first $200 \mathrm{mg}$ mifepristone which has antiprogesterone action. Rabiei S et al. [2] study using $600 \mathrm{~g}$ misoprostol sublingually and vaginally repeated 6 hourly found that complete abortion in sublingual and vaginal group was $96 \%$ and $90 \%$ respectively. The higher success rate may be related to higher dose $600 \mathrm{~g}$ misoprostol used in this study.

Nausea and vomiting reported in 24 (20.00\%) cases and require treatment. Other frequently reported adverse effects were diarrhoea (more than 4 episodes) in $20(16.67 \%)$. Fever /chills treatment required in 18 $(15.00 \%) . \quad 8 \quad(6.67 \%)$ women reported excessive bleeding. This may be explained by the high bioavailability of sublingual misoprostol. Most patients considered the side-effect to be tolerant and transient and found that they decreased gradually after the first dose of treatment. Similar observation was made by Tanha FD et al. [17] found that although the effectiveness was high in sublingual group than in vaginal group, the sublingual experienced more prevalence rate of bleeding, pain severity, diarrhoea and fever. Shah $\mathrm{N}$ et al. [12] found that incidence of sideeffects was three times more in sublingual group than in vaginal group. The most common being an unpleasant taste $(60 \% \mathrm{v} / \mathrm{s} 4 \%)$, nausea $(20 \% \mathrm{v} / \mathrm{s} 4 \%)$ and shivering (24\% v/s 16\%).

\section{CONCLUSION}

From our study, we conclude that sublingual misoprostol is the effective route for the medical management of missed abortion in first trimester.

Management of missed abortion by misoprostol avoids the need of surgical evacuation and hence no anaesthesia and thereby avoiding complications due to these. Misoprostol tablet has of advantage low cost, long shelf life, lack of need of refrigeration and its easy availability. Thus, it may be advocated to be used in outpatient setting in treatment of early pregnancy failure even at the primary care level and thereby decreasing sepsis and morbidity due to it.

\section{REFERENCES}

1. Schorge JO, Schaffer JI, Halvorson LM. Firsttrimester abortion. In: Schorge JO, Schaffer JI, editors. Williams Gynecology. New York: McGrawHill; 2008.

2. Rabiei S, Khansari S, Fallah M, Ajand M. Comparison of sublingual versus vaginal misoprostol in the management of missed abortions. Biomed Res Ther. 2019; 6(10):3391-3395.

3. Geyman JP, Oliver LM, Sullivan SD. Expectant, medical, or surgical treatment of spontaneous abortion in first trimester of pregnancy? A pooled quantitative literature evaluation. J Am Board FAM Pract. 1999; 12(1):55-64.

4. Bagratee JS, Khullar V, Regan L, Moodley J, Kagoro H. A randomized controlled trial comparing medical and expectant management of first trimester miscarriage. Hum Reprod. 2004; 19:266-71.

5. Chia KV, Oqbo VI. Medical termination of missed abortion. J Obstet Gynaecol. 2002; 22:184-6.

6. Aly HH, Sokkary HE. Comparison between Sublingual and Vaginal Administration of Misoprostol in Management of Missed Abortion. The Journal of Obstetrics and Gynaecology of India. Septeber-October. 2016;66(S1):S24-S29.

7. Wu HL, Marwah S, Wang P, Wang OM, Chen XW. Misoprostol for medical treatment of missed abortion: a systematic review and network meta-analysis. Sci Rep. 2017 May 10;7(1):1664.

8. Ngai SW, Chand YM, Tang O, Ho PC. Vaginal misoprostol as medical treatment for first trimester spontaneous miscarriage. Hum Reprod. 2001; 7:1493e1496.

9. Singh K, Fong YF, Prasad RN, Dong F. Does an acidic medium enhance the efficacy of vaginal misoprostol for pre-abortion cervical priming? Hum Reprod. 1999; 14:1635-7.

10. Ho PC, Ngai SW, Liu KL, Wong GCY, Lee SW. Vaginal misoprostol compared with oral misoprostol in termination of second trimester pregnancy. Obstet Gynecol. 1997; 90:735-8.

11. American College of Obstetricians and Gynecologists. Medical management of abortion. In: ACOG, eds. Practice Bulletin No 67. USA: ACOG; Reaffirmed. 2005-2009.

12. Shah N, Azam SI, Khan NH. Sublingual versus vaginal misoprostol in the management of missed miscarriage. J Pak Med Assoc. 2010 Feb; 60(2):113-6.

13. Park JY, Ahn HJ, Yoo BR, Hwang KR, Lee TS, Jeon HW, Kim SM and Kim BJ. Effectiveness and safety of sublingual misoprostol in medical treatment of the 1st trimester miscarriage: experience of off-label use in Korea. Obstet Gynecol Sci. 2018 Mar; 61(2): 220 226.

14. Sharma P, Sharma S, Sharma M. Comparison between sublingual and vaginal route of misoprostol in management of first trimester missed abortion. International Journal of Medical and Health Research. November. 2018;4(11):101-103.

15. Thakur S, Pratap C. Comparison between sublingual 600 and 800 microgram misoprostol after mifepristone for MTP up to 9 weeks gestation. Int J Reprod Contracept Obstet Gynecol. 2018 Dec;7(12):4996-5004..

16. Tanha FD, Feizi M, Shariat M. Sublingual versus vaginal misoprostol for the management of missed abortion. J Obstet Gynaecol Res. 2010 Jun;36(3):52532. 